\title{
Perspectiva de discapacidad y derechos humanos en el contexto de una educación superior inclusiva
}

\author{
Perspectiva sobre deficiência e direitos humanos no contexto do ensino superior \\ inclusivo
}

\section{Disability and human rights perspective in the context of inclusive higher education}

\author{
Agustina Palacios*
}

\section{Resumen}

La educación inclusiva no se limita al derecho de las personas con discapacidad al acceso, permanencia y egreso en igualdad de oportunidades. Supone e implica asimismo una metodología y una serie de contenidos tanto en la formación académica como en la investigación, extensión y transferencia universitaria. Dichos contenidos se corresponden con la perspectiva en discapacidad y derechos humanos desde una mirada transversal, interseccional y transdisciplinar, que favorezca la consolidación de saberes diversos e integrales. A dichos fines, se hace necesario generar conciencia, formar y vincularnos desde los principios que sustentan una mirada centrada en la persona, potenciando y habilitando su autonomía y protagonismo.

Palabras claves: Discapacidad. Derechos humanos. Educación inclusiva. Formación profesional.

\section{Resumo}

A educação inclusiva não se limita ao direito das pessoas com deficiência ao acesso, permanência e egresso em igualdade de oportunidades. Também implica uma metodologia e uma série de conteúdos, tanto na formação acadêmica quanto na pesquisa, extensão e transferência universitária. Esses conteúdos correspondem à perspectiva sobre deficiência e direitos humanos a partir de uma perspectiva transversal, interseccional e transdisciplinar que favoreça a consolidação de conhecimentos diversos e integrais. Para esse fim, é necessário gerar conscientização, treinar e vincular os princípios que sustentam um olhar centrado na pessoa, fortalecendo e habilitando sua autonomia e protagonismo.

Palavras-chave: Deficiência. Direitos humanos. Educação inclusiva. Formação profissional.

\section{Abstract}

Inclusive education is not limited to the right of persons with disabilities to access, stay and leave on equal opportunities. It also implies and implies a methodology and a series of contents both in academic training and in research, extension and university transfer. These contents correspond to the perspective on disability and human rights from a transversal, intersectional and transdisciplinary perspective, which favors the consolidation of diverse and integral knowledge. For these purposes, it is necessary to generate awareness, train and link from the principles that support a person-centered look, empowering and empowering their autonomy and prominence.

Keywords: Disability. Human rights. Inclusive education. Vocational training.

\footnotetext{
Doctora en Derecho por la Universidad Carlos III de Madrid. Programa Derechos Humanos, Instituto de Derechos Humanos "Bartolomé de las Casas". Profesora Adjunta de Derecho Político y Profesora de Derechos Humanos y Garantías Constitucionales, Facultad de Derecho, Universidad Nacional de Mar del Plata. Investigadora Adjunta del CONICET (Consejo Nacional de Investigaciones Científicas y tecnológicas de Argentina). Directora del Área Discapacidad y Derechos Humanos, Centro de Investigación y Docencia en Derechos Humanos "Alicia Moreau", Facultad de Derecho, Universidad Nacional de Mar del Plata. Relatora Argentina de la Red Iberoamericana de Expertos en la Convención Internacional sobre los Derechos de las Personas con Discapacidad. Directora Grupo de Investigación sobre Discapacidad, Sociedad y Derechos Humanos, Facultad de Derecho, Universidad Nacional de Mar del Plata (OCA 108/2012). Directora de la Clínica Jurídica en Discapacidad y Derechos Humanos", Facultad de Derecho, Universidad Nacional de Mar del Plata. Mar del Plata - Argentina. E-mail: aguspalacios@hotmail.com.
} 


\section{Introducción}

Hace décadas que desde el movimiento de personas con discapacidad se viene reclamando un cambio de paradigma a la hora del abordaje y tratamiento de la discapacidad. Desde el activismo político, esta reivindicación ha sido plasmada a través del movimiento de vida independiente (que se originó en Estados Unidos en la década de los años setenta, y ha tenido clara influencia a nivel mundial) (SHAPIRO, 1994). Desde el ámbito académico, esto se ha reflejado en una evolución desde un modelo de abordaje de la discapacidad netamente médico/rehabilitador hacia un modelo denominado social (cuyas bases teóricas se concibieron en la misma época en el Reino Unido) (BARNES, 1998; BARNES; MERCER, 2003). En las últimas décadas se ha profundizado en un nuevo enfoque, que puede resumirse en la concepción de la discapacidad como cuestión de derechos humanos (DE ASIS, 2013; PALACIOS, 2008). El derecho internacional de los derechos humanos incorpora este abordaje a partir de la aprobación de la Convención Internacional sobre los Derechos de las Personas con Discapacidad (CDPD).

Dicho Tratado internacional impone el cumplimiento de ciertos estándares relacionados con el contenido (derechos humanos) y la participación (de las personas con discapacidad) en la educación universitaria. Así, la educación inclusiva no solo es el derecho de las personas con discapacidad al acceso, permanencia y egreso a la Universidad en igualdad de oportunidades, sino que asimismo implica una metodología y una serie de contenidos en la formación de estudiantes - futuros/as profesionales.

Esta formación, sin embargo, no suele ser abordada en los sistemas de educación superior de forma suficiente ni integrada. ${ }^{1}$ En el ámbito del Derecho, por ejemplo, resulta común observar la falta de formación de profesionales frente a casos que involucran a personas con discapacidad en los diversos fueros (FERNANDEZ, 2016). En consecuencia, suele también identificarse la falta de perspectiva de discapacidad y derechos humanos en la elaboración de dictámenes, informes, pericias, resoluciones y sentencias judiciales. ${ }^{2}$ Un ámbito concreto que resulta ilustrativo es en materia de capacidad jurídica, donde se percibe una necesaria actualización en los nuevos paradigmas, (IGLESIAS, 2016) a pesar de que son varias las reformas jurídicas que se vienen llevando adelante en el espacio iberoamericano. ${ }^{3}$ (BARIFFI, 2014).

Esta necesidad de formación viene siendo visibilizada a partir de documentos y normas-como por ejemplo las 100 Reglas de Brasilia sobre acceso a la justicia de las personas en condición de vulnerabilidad; y los Protocolos de Acceso a la justicia para personas con discapacidad que se han realizando en diversos

Este texto se enmarca en las reflexiones y aportes del Proyecto Interfacultades titulado "Perspectiva de discapacidad y derechos humanos desde una mirada transdisciplinar. Su inclusión en la formación, prácticas e intervenciones profesionales del Derecho, Trabajo Social, Terapia Ocupacional, Medicina, Psicología y Arquitectura en la ciudad de Mar del Plata, PI3cET 2019-2020, UNMDP, Dirección: Agustina Palacios, Codirección: Rubens Ramón Méndez, Coordinadora de Extensión: María Laura Tejón, Coordinadora de Transferencia: Julieta Villa, Integrantes: Adobbati, David; Alvarez, Natalia; Bru, Gabriela; Consoli, Pilar; Dartizio, Rosana; Defalco Rosana; Demarchin Nora; Fernandez, Silvia Eugenia; lanantuony, Carola; Iglesias, Maria Graciela; Manzilla, Romina B.; Martina, Pia; Martinucci, Victoria; Mendez, Marina; Slavin Estefi; Sponer, Marisol; Valente Laura; Valente, Laura; Zingales, Paula Andrea.

Un máximo y vergonzoso exponente ha sido, en Argentina, una sentencia del fuero penal en la que jueces de segunda Instancia (Cámara de Apelaciones), han manifestado las siguientes expresiones en relación a la posibilidad o no de consentir relaciones sexuales de una mujer con discapacidad frente a un caso de violación. Así, han expresado: - "como el ser humano es humano en cuanto habla, piensa, vive en sociedad [...], no en cuanto mera entidad biológica, el consentimiento que interesa es el que resulta de esa capacidad [...]. Si no la tiene, o está gravemente mermada, entonces reacciona (consiente o rechaza) poco más (o menos) que como un animal. Esto es, para el Derecho, como un objeto, una cosa, no como un humano, una persona. [...] damos por sentado [...] que un débil mental, aún profundo (un idiota, por ejemplo), un demente o un psicótico o delirante grave no por ello está excluido de la especie humana ; [...] ]es claro que si admitiéramos que es capaz de un amor humano -no de un simple afecto animal- estaríamos juzgando que es capaz de consentir.; [...] se autorizaría una copulación más animal que humana y habría que asegurarse de que haya algo del orden del amor, lo cual, por parte del discapacitado moderado o grave, es, como decía antes, imposible, haciendo la cuestión muy espinosa; [...]. No podía ir mucho más lejos que un cachorro que cuando llega el dueño se baja apresuradamente del sillón donde dormía plácidamente; y cuando se va, vuelve a subirse, puede aprender, como el cachorro, algunas consignas simples y sentir preocupación o temor al castigo si no las cumple" [...] "Basta con ir al zoológico y pararse frente a la jaula de los monos... no muy cerca, mejor". Cfr, Sentencia № 18/2.010, Cámara en lo Criminal de Segunda de Neuquén en autos caratulados: "I., H. A. s/Abuso Sexual", Expte.n 50- año 2009.

Cfr. Reforma y Unificación del Código Civil y Comercial de la Nación Argentina en 2015; Ley No. 9379, Ley para la promoción de la autonomía de las personas con discapacidad, Costa Rica, de 2016; Decreto Legislativo 1384 que reconoce y regula la capacidad jurídica de las personas con discapacidad en igualdad de condiciones en Perú, de 2018; Ley 1996 mediante la cual se establece el régimen para el ejercicio de la capacidad jurídica de las personas con discapacidad mayores de edad en Colombia, de 2019. 
países. ${ }^{4}$ Así, por ejemplo Protocolo Iberoamericano de Actuación Judicial para mejorar el acceso a la justicia de personas con discapacidad, migrantes, niñas, niños, adolescentes, comunidades y pueblos indígenas, establece la necesidad adopción de

medidas transformativas [...] ya sean culturales, actitudinales, en la infraestructura física, o en el contenido de los procesos y decisiones de las autoridades, para que sea ejercido en igualdad de condiciones que el resto de la población sin discapacidad, lo que dará pauta a que gocen y ejerzan plenamente todos sus demás derechos. ${ }^{5}$

En igual sentido, las Reglas de Brasilia actualizadas requieren la adopción de

medidas destinadas a la especialización de quienes operan el sistema judicial y de quienes intervienen de una u otra forma en su funcionamiento, para la atención de las personas en condición de vulnerabilidad y en particular, las víctimas necesitadas de especial protección y a personas menores de edad con discapacidad. ${ }^{6}$

De igual modo, en las carreras relacionadas con las Ciencias de la Salud, el Trabajo Social y la Terapia Ocupacional, los abordajes sobre temáticas referentes a la discapacidad, los derechos humanos y su relación con la CDPD resultan insuficientes. Los contenidos curriculares en la formación de las asignaturas suelen centrarse en modelos basados en lo biomédico, desde un binomio salud-enfermedad. Las prácticas de intervención profesional siguen un patrón asistencialista, desde un modelo médico-rehabilitador, centrado en un diagnóstico de la persona que suele llegar a colonizar su vida (BRU, 2016). Otro ámbito en el que la perspectiva suele estar ausente es en las carreras de Arquitectura y Urbanismo, donde la formación sigue un patrón androcéntrico de lógica patriarcal y capacitista (SERRA, 2017, p. 28), orientado a un individuo universal adulto, neutro (masculino), en estado óptimo de salud y de medidas estándar, lo que repercute en el hacer arquitectura y hacer ciudad (SLAVIN, 2019).

Por lo antedicho, la educación y formación en discapacidad y derechos humanos es hoy en día una herramienta ineludible para alcanzar una participación profesional activa y transformadora de las realidades sociales (DEMARCHI; LAZZARI, 2014). Pero a dichos fines, se hace necesario generar conciencia, formar y vincular a las profesiones y sobre todo a quienes las ejercen, "desde y hacia" una mirada centrada en la persona, desde los principios que sustentan su autonomía y protagonismo.

\section{Algunas notas sobre la perspectiva de discapacidad y derechos humanos}

Resulta constante enfrentar concepciones y abordajes profesionales que dejan en evidencia la falta de formación y capacitación en materia de discapacidad (LIDÓN HERAS, 2016). Ello sin duda genera situaciones de discriminación y vulneración de derechos. Por ende, la perspectiva de discapacidad y derechos humanos implica y requiere, en primer término, que al igual que la perspectiva de género, ciertos contenidos en materia de derechos de las personas con discapacidad sean introducidos en la educación superior desde una mirada transversal, interseccional y transdiciplinar, favoreciendo la consolidación de saberes polisémicos, diversos e integrales (IANANTUONY, 2013).

La mirada requiere ser transversal, dando lugar a comprensiones integrales, saberes entrelazados y discursos de complementariedad (BRU, 2012). Una contemplación integral, que se traslade a personas situadas y contextualizadas, con sus potencialidades, deseos, barreras u obstáculos....Asimismo, el enfoque requiere ser transdiciplinar, dado que en el campo de la discapacidad los discursos disciplinares parcializan,

Cfr. Reglas de Brasilia sobre acceso a la justicia de las personas en condición de vulnerabilidad, (Actualización aprobada por la Asamblea Plenaria de la XIX edición de la Cumbre Judicial Iberoamericana, abril de 2018, Quito-Ecuador), Protocolo para el Acceso a la Justicia de las Personas con Discapacidad Colección Documentos de Política n 2 Área Justicia, Ministerio Público de la Defensa, Eurosocial, Argentina, 2013 Protocolo Iberoamericano de actuación judicial para mejorar el acceso a la justicia de personas con discapacidad, migrantes, niñas, niños, adolescentes, comunidades y pueblos indígenas, México, Suprema Corte de Justicia de la Nación, 2014 Protocolo de Atención Judicial para Personas con Discapacidad" R.A. Nº10-2018-CE-PJ, Perú, 2018.

5 Protocolo Iberoamericano de actuación judicial para mejorar el acceso a la justicia de personas con discapacidad, migrantes, niñas, niños, adolescentes, comunidades y pueblos indígenas, Suprema Corte de Justicia de la Nación de México, 2014, p.233.

Reglas de Brasilia, cit. Regla 40. 
y ninguna disciplina, de manera aislada, es capaz de ahondar en su complejidad. A dicho fin es necesario ir incluso más allá de las disciplinas, superando la fragmentación del conocimiento, abarcando una realidad interactuante, que no puede ser analizada solo "entre" o "a través" de las diferentes disciplinas, sino "más allá" de toda disciplina (PEÑUELA VELAZQUEZ, 2005, p. 44). Finalmente, es imperioso sumar el paradigma de la interseccionalidad, concebida como una herramienta de análisis, necesaria para comprender, en este caso, la discapacidad y su cruce con diversas identidades - como lo son el género y la edad, entre otras -, y el modo en que dichos cruces contribuyen a experiencias únicas de opresión y/o privilegio (CRENSHAW, 1989; BARRERE UNZUETA, 2010; MENDEZ, 2016).

Así, desde el intercambio e intersecciones de saberes y experiencias, será posible concebir un nuevo enfoque, a la luz de los contenidos teóricos elaborados desde el aporte de diferentes disciplinas, desde el protagonismo y participación de las personas con discapacidad, desde su concepción como problemática social y desde los valores que sustentan a los derechos humanos.

\subsection{Reformulación del concepto de discapacidad}

El primer paso necesario para una educación inclusiva es un cambio en la mirada. La reconceptualización de la discapacidad como un "problema socio-político, cuya causalidad estructural se sitúa en el régimen de organización social, económica, política y cultural vigente en una sociedad y en un momento histórico determinado". (MAREÑO SEMPERTEGUI, 2006, p. 1). EI modelo social de discapacidad visibilizó las causas sociales, culturales, y contextuales de la discapacidad (PALACIOS, 2008). Y hoy en día no es posible ignorar tres facetas o dimensiones que interaccionan y deben estar presentes en cualquier análisis sobre la materia (BROGNA, 2009).

La primera es la condición de discapacidad, que es la dimensión personal. El modo en que se defina y conciba esta condición sin duda va a tener incidencia en la identidad de la persona. Si ésta surge exclusivamente desde un diagnostico médico, -como el de deficiencia-, entonces se convierte en una identidad de la insuficiencia, la carencia y la falta de autonomía (FERREIRA, 2008, p. 6). Desde dicha concepción asilada se hace muy difícil construir una identidad. ${ }^{7}$ En cambio, si esta dimensión surge desde el concepto de diversidad humana, la identidad será configurada en términos descriptivos y no negativos. Es por ello que se propone el término diversidad funcional- en remplazo del término "deficiencia", o "padecimiento" porque de este modo se elimina la connotación negativa sobre las palabras que aluden a las características de un ser humano (PALACIOS; ROMAÑACH, 2007, p. 34-37).

La segunda dimensión a tener en cuenta es la situación de discapacidad. La dimensión interrelacional, situacional y dinámica, que surge cuando entran en juego las barreras sociales (BROGNA, 2009). Esta situación "discapacita", restringe y/o impide el ejercicio de derechos en igualdad de condiciones con les demás. Ha sido puesta de manifiesto desde el activismo político y el modelo social de discapacidad desde la década de los años setenta del Siglo pasado.

La tercera dimensión es la posición de discapacidad, que es estructural. Se sitúa en las representaciones, en las valoraciones, en la cultura, siendo el resultado de nuestros prejuicios y estereotipos (BROGNA, 2009, p. 23). Es necesario, por ende, tomar conciencia respecto de que la posición de discapacidad se relaciona con el valor que le asignamos a esa condición y a esa situación... Y como expresa Ferreira (2008, p. 4), ${ }^{8}$ la representación social de la discapacidad no suele ser la de la diversidad, sino la de la deficiencia, de la minus-valia -asimilada al déficit, a lo "anormal", a la incapacidad...

Por ello, es importante volver a traer al debate la condición personal -diversidad funcional-, deconstruyendo la perspectiva médica, desde el relato vivencial de sus protagonistas. La deconstrucción del mismo concepto de discapacidad desde una mirada transdiciplinar requiere introducir en la política de la discapacidad la experiencia de la diversidad funcional desde el relato de quienes son sus protagonistas. En palabras de

Distinto es el caso de aquellas personas Sordas que se consideran pertenecen a una minoría cultural y lingüística. (CUENCA GOMEZ, 2011). Ferreira (2008, p. 4) ha propuesto el término de alter-valia para contrarrestar esa percepción y concepción. 
Crow (1996, p. 57), debe hacerse "porque si no se imponen estas definiciones y perspectivas, el mundo no discapacitado seguirá haciéndolo por las personas con discapacidad, y lo hará de manera descalificadora".

Quizás uno de los mayores desafíos en esta instancia radique en la construcción de una identidad de las personas con discapacidad desde el propio movimiento que trascienda la condición como biológica, natural y deficitaria. A dicho fin, se hace necesario profundizar la concepción del tema como cuestión de derechos humanos. Concebir la discapacidad desde los derechos humanos nos obliga a deconstruir

todo lo que nos ha sido pensado desde la academia, desde los textos expertos, desde los discursos políticamente correctos, desde las acomodadas conciencias de quienes se saben formando parte de la normalidad, de lo racional, de lo democrático, de lo verdaderamente humano, es lo que provoca la relación directa y abierta con quienes no forman parte de todas estas certezas. (PÉREZ DE LARA, 2001, p. 10).

\title{
2.2 La discapacidad como cuestión de derechos humanos
}

Al igual que sucede en la temática de género, es importante que las gafas que utilicemos al abordar cualquier asunto relativo a la discapacidad estén impregnadas de su consideración como cuestión de derechos humanos. Lo que sin duda nos obliga a nutrir esa mirada desde los valores y principios que los sustentan.

La CDPD cumple una función muy importante al situar la discapacidad como cuestión de derechos humanos. Ello supone dejar de ver a las personas como problemas para pasar a considerarlas titulares de derechos; como asimismo significa centrar la atención en el modo en que los diferentes procesos económicos, sociales y culturales tienen presente o no "la diferencia implícita en la discapacidad". (QUINN; DEGENER, 2002). Así, las personas con discapacidad dejan de ser objeto de políticas asistenciales para pasar a ser "sujetos de derecho". Y para proteger y garantizar el ejercicio de derechos en igualdad de condiciones y sin discriminación por motivo de discapacidad, el Tratado aborda cada uno de los derechos en el contexto específico de este colectivo.

El artículo 3 establece los principios rectores, a los fines de la interpretación y aplicación del Tratado. Estos son:

\begin{abstract}
a) El respeto de la dignidad inherente, la autonomía individual, incluida la libertad de tomar las propias decisiones, y la independencia de las personas; b) La no discriminación; c) La participación e inclusión plenas y efectivas en la sociedad; d) El respeto por la diferencia y la aceptación de las personas con discapacidad como parte de la diversidad y la condición humanas; e) La igualdad de oportunidades; f) La accesibilidad; g) La igualdad entre el hombre y la mujer; h) El respeto a la evolución de las facultades de los niños y las niñas con discapacidad y de su derecho a preservar su identidad. ${ }^{9}$
\end{abstract}

La lectura atenta de esta norma nos muestra que la CDPD incorpora diferentes dimensiones de los valores y principios que sustentan a los derechos humanos. La columna rectora es la dignidad, entendida como una condición inescindible de la humanidad. La libertad entendida como autonomía - en el sentido de desarrollo del sujeto moral - que exige entre que la persona sea el centro de las decisiones que le afecten. Y la igualdad inherente de todo ser humano - respetuosa e inclusiva de la diferencia -, la cual asimismo exige la satisfacción de ciertas necesidades básicas (PALACIOS, 2008, p. 154). Ello ha generado una mirada diferente hacia la persona con discapacidad, centrada en primer término en su concepción como ser humano, en igualdad de derechos y dignidad que los demás, y en segundo lugar en una condición (la diversidad funcional) que le acompaña, y que requiere en determinadas circunstancias de medidas específicas para garantizar el goce y ejercicio de los derechos, en igualdad de condiciones que el resto de personas.

De este modo, concebir la discapacidad como cuestión de derechos humanos no se reduce a una mera cuestión terminológica, sino que produce consecuencias en el ámbito normativo, en el ámbito dikelógico y en el sociológico (GOLDSCHMIDT, 1976). ${ }^{10}$

\footnotetext{
Articulo 3 CDPD

Cfr. la teoría trialista del derecho, planteada por Goldschmidt (1976).
} 
En el ámbito normativo, tanto los instrumentos de derecho internacional de los de derechos humanos como las normas del derecho interno de los diversos países han venido legislando la temática desde dicha perspectiva (en este punto la CDPD es el ejemplo más paradigmático). En el ámbito dikelógico, esta concepción nos obliga a replantearnos la discapacidad desde el discurso de los derechos humanos, lo que nos lleva a deconstruir la misma idea de dignidad humana, desde otra concepción que trascienda perspectivas basadas en las capacidades, o en determinadas características y/o condiciones de las personas (DE ASIS, 2013; NUSSBAUM, 2012). Asimismo, comporta consecuencias en la dimensión sociológica, que exigen otra visión a la hora del diseño e implementación de políticas públicas en la materia. (ACUÑA; BULIT GOÑI, 2010).

La exigencia de dejar de considerar a las personas con discapacidad como objeto de políticas asistenciales para pasar a hacerlo como titulares y sujetos de derechos, requiere en primer lugar reconocer y respetar la diversidad funcional de una persona como un elemento natural de la diversidad humana, en el mismo sentido que el género. Desde allí es posible abordar los prejuicios específicos de la discapacidad, las actitudes, y otras barreras para el disfrute de los derechos humanos. Ello además importa asumir la responsabilidad de asegurar que los derechos sean ejercidos sin discriminación por motivo de discapacidad, tanto por parte del Estado (principal responsable), como por parte de la sociedad. Finalmente, esto también implica incorporar el enfoque de derechos humanos, el cual

b) subraya que, los derechos reconocidos en tratados y pactos internacionales requieren medidas positivas de los Estados para que su vigencia sea efectiva. Estas medidas positivas se traducen en políticas públicas cuya definición corresponde ya sea al Poder Legislativo o al Ejecutivo, y cuya implementación se encuentra a cargo de este último. A partir de allí se estructura un andamiaje conceptual, pero a la vez teórico-operativo, que identifica diversos mecanismos de seguimiento y responsabilidad que involucran a los actores políticos, sociales y económicos en el proceso de definición de políticas, incorporando el principio de igualdad y no discriminación, como también de responsabilidad. (PAUTASSI, 2010, p. 4).

\subsection{La toma de conciencia y la necesaria inclusión de una perspectiva de discapacidad en la educación superior}

La perspectiva, el enfoque y la concepción de la discapacidad como cuestión de derechos humanos no solo es una exigencia a la hora del diseño e implementación de la política pública, sino que es una herramienta imprescindible en la formación universitaria y el ejercicio profesional. ${ }^{11}$ Sin embargo, como se ha mencionado, las prácticas e intervenciones profesionales suelen poner de manifiesto la falta de formación y perspectiva sobre discapacidad y derechos humanos desde una mirada transversal, interseccional y holística. A ello se le suma que las personas con discapacidad no acceden a la educación superior, o cuando lo hacen enfrentan barreras que en muchas ocasiones se originan precisamente por dicha falta de capacitación y formación en discapacidad, por parte de docentes, personal no docente y/o profesionales. ${ }^{12}$ Por ello, la CDPD ha establecido como necesaria y urgente "la formación de profesionales y el personal que trabajan con personas con discapacidad respecto de los derechos reconocidos en la presente Convención, a fin de prestar mejor la asistencia y los servicios garantizados por esos derechos". ${ }^{13}$

Dicha formación y/o capacitación es requerida tanto por las propias personas con discapacidad - como herramienta de empoderamiento y activismo político-, como por profesionales que intervienen y/o acompañan los procesos. Asimismo se hace necesaria para la eliminación de barreras arquitectónicas, actitudinales y/o comunicacionales, debidas a prácticas inadecuadas históricamente arraigadas, que derivan en situaciones

\footnotetext{
1 En Argentina, esto ha sido puesto de manifiesto por la Cámara de Diputados de la Nación en su el proyecto por el cual se solicita al "Poder Ejecutivo, el Consejo Interuniversitario Nacional y el Consejo de Rectores de Universidades Privadas, cada uno en el ámbito de su competencia, transmitan el interés de esta Honorable Cámara de que se incorpore en las carreras de los institutos de educación superior y de las instituciones de educación universitaria, contenidos curriculares que contemplen los distintos aspectos de la discapacidad en la formación profesional de los graduados". Ello en las Carreras de carreras de derecho, de arquitectura, de educación física y de medicina respectivamente. Cfr. OD 174, 16 de Junio de 2016. http://www4.diputados.gov.ar/dependencias/dcomisiones/periodo-134/134-174.pdf.

12 CRPD/C/GC/4, Observación General Nro.4 sobre el derecho a la educación inclusiva del Comité Internacional sobre los Derechos de las Personas con Discapacidad, 26/11/2016.

13 Art. 4 inc. i Convención Internacional sobre los Derechos de las Personas con Discapacidad.
} 
de discriminación y violación de derechos. ${ }^{14}$ Por otro lado, el enfoque de derechos humanos en discapacidad produce transformaciones en el ejercicio profesional, dada la comprensión de las demandas que se presentan de manera compleja, holística y desde un proceso participativo. Es por ello que la formación en perspectiva de discapacidad y derechos humanos es a la vez una herramienta de concientización y formación para la ejecución de prácticas y acciones alineadas con los principios y contenidos de la CDPD.

Ello se enmarca, asimismo, en la exigencia de toma de conciencia (prevista en el art 8 CDPD) que exige la capacitación de les distintos/as operadores/as que transversalmente intervienen o despliegan acciones frente al ejercicio de derechos de las personas con discapacidad. ${ }^{15}$

La norma se centra en el Estado, la sociedad y la familia. Obligación primaria del Estado, la concepción de la discapacidad desde el enfoque de los derechos humanos (y sus importantísimas implicancias en el diseño, implementación y ejecución de la política pública). La sociedad y la familia, como parte esencial de esta interacción voluntaria o involuntaria que incluso muchas veces genera o agrava genera esta situación y/o posición de discapacidad. Y a esto haría falta sumar el necesario protagonismo de las personas con discapacidad, dado que la toma de conciencia implica empoderamiento, participación y autonomía (PALACIOS, 2018).

El lema "nada sobre las personas con discapacidad sin las personas con discapacidad", ha sido reflejado en el art. 4 de la CDPD al exigir que

c) en la elaboración y aplicación de legislación y políticas para hacer efectiva la presente Convención, y en otros procesos de adopción de decisiones sobre cuestiones relacionadas con las personas con discapacidad, [...] se celebrarán consultas estrechas y colaborarán activamente con las personas con discapacidad. ${ }^{16}$

En este sentido la OG4 del Comité sobre los Derechos de las Personas con Discapacidad ha destacado que "los Estados partes deben consultar y colaborar activamente con las personas con discapacidad [...] en todos los aspectos de la planificación, aplicación, supervisión y evaluación de las políticas de educación inclusiva." ${ }^{17}$ Y que en dicho caso las personas con discapacidad no solo son beneficiaras de la educación, sino colaboradoras en estos procesos. ${ }^{18}$

En consecuencia, esta "toma de conciencia", tal cual la plantea la norma citada, no es una opción, sino, sin duda, una obligación derivada de varias otras normas, entre las que se destaca el art. 3 (principios generales), el art. 4 (obligaciones específicas), y el art. 24 (educación inclusiva). La exigencia de profesionales con formación y capacitación en la materia conlleva una obligación en el ámbito de la Educación Superior. En este punto merece destacarse la Observación General del Comité sobre los Derechos de las Personas con Discapacidad, sobre Educación Inclusiva que concibe a la inclusión como un proceso, que sin duda requiere la transformación del sistema educativo. ${ }^{19}$

\section{Algunas notas sobre el contenido y alcance del derecho a la educación superior inclusiva}

En el marco del derecho internacional de los derechos humanos, la educación se encuentra reconocida en una serie de instrumentos y Tratados. ${ }^{20}$ Dichos instrumentos reconocen el derecho a la educación de todas

\footnotetext{
4 Resulta ilustrativo un caso de Argentina, en el cual se detectó que el actuar de los peritos había demostrado "lisa y llanamente un soberano desconocimiento de los Tratados de Derechos Humanos, en especial de la Convención de los Derechos de las Personas con Discapacidad y una discriminación intolerable" hacia la persona. A fin de reparar "esa manera tan limitada de pensar y abordar a personas con discapacidad [...]"se impuso que dichos profesionales realizaran con carácter obligatorio, un curso sobre la temática (N., G. A. Proceso de restricción de capacidad, Expte. No 409.802/12), elDial.com - AA9025, 2015.

5 Art. 8 CDPD.

Art. 4 CDPD.

OG4, parr. 7

Idem.

CRPD/C/GC/4, Observación General Nro.4 sobre el derecho a la educación inclusiva, cit.

Entre otros, la Declaración Universal de Derechos Humanos, el Pacto de Derechos Económicos, Sociales y Culturales, la Convención contra toda forma de Discriminación Racial, la Convención para la eliminación de toda Forma de Discriminación contra la mujer, y la Convención de Derechos del Niño. Asimismo las Normas y la Declaración de Salamanca.
} 
las personas. Sin embargo, a partir de la CDPD es donde se reconoce no solo el derecho a la educación a secas, sino el derecho a una educación "inclusiva" ${ }^{21}$ El derecho no es a cualquier tipo de educación, sino a una educación inclusiva. Así lo ha definido la Observación General Nro. 4 del Comité sobre los Derechos de las Personas con Discapacidad, que aborda el significado de un "sistema de educación inclusivo", que concibe a la inclusión como un proceso, que requiere la transformación del "sistema educativo", que involucra a todos los actores (alumnado, cuerpo docente, no docente). Que a su vez requiere dinamismo y flexibilidad, para alcanzar una participación efectiva, instrucción personalizada y pedagogía inclusiva. ${ }^{22}$

La OG4 ha desarrollado el contenido y alcance jurídico del derecho, y las obligaciones consecuentes. Y ha dejado en claro que garantizar el derecho a la educación es una cuestión tanto de acceso "como de contenido", y los esfuerzos deben encaminarse a fomentar el respeto de una amplia gama de valores, como la comprensión y la tolerancia. ${ }^{23}$ Por ende, la educación inclusiva debe tener por objeto promover el respeto mutuo y el valor de todas las personas, creando entornos educativos en los que el enfoque educativo, la cultura de la institución educativa y los propios planes de estudios reflejen el valor de la diversidad. ${ }^{24}$

Esto último tiene intima relación con la incorporación de contenidos curriculares que contemplen los distintos aspectos de la discapacidad - desde la perspectiva de derechos, acorde con las disposiciones de la CDPD y el paradigma del modelo social. Es decir, una educación superior inclusiva entendida como la formación de futuros/as profesionales capacitados/as para respetar, proteger y promover los derechos de las personas con discapacidad al momento de ejercer en los diferentes ámbitos. Respecto de esta segunda faceta, se parte de la afirmación de que, para las personas con discapacidad, es central que los/las profesionales con quienes tratan en los distintos aspectos de su vida cuenten con una suficiente preparación para brindar un servicio adecuado, respetando su voluntad y en concordancia con los mencionados estándares establecidos por la CDPD y el modelo social. La OG4 destaca esta cuestión e incluso define como

d) barreras que impiden a las personas con discapacidad acceder a la educación inclusiva [...] el hecho de no entender o aplicar el modelo de derechos humanos de la discapacidad, según el cual las barreras en la comunidad y la sociedad, en lugar de deberse a deficiencias personales, excluyen a las personas con discapacidad;. ${ }^{25}$

Como asimismo "la falta de voluntad política y de capacidad y conocimientos técnicos para hacer efectivo el derecho a la educación inclusiva, lo que incluye la capacitación insuficiente de todo el personal docente." ${ }^{26}$

Por ello, garantizar el derecho a la educación inclusiva "conlleva una transformación de la cultura, la política y la práctica en todos los entornos educativos formales e informales para dar cabida a las diferentes necesidades e identidades de cada alumno, así como el compromiso de eliminar los obstáculos que impiden esa posibilidad." ${ }^{27}$ Ahora bien, para hacer efectivo el derecho a le educación inclusiva, las personas con discapacidad deben tener "acceso" en igualdad de condiciones que el resto de personas, lo que implica asimismo un acceso sin discriminación por motivo de discapacidad. Esto nos conduce al valor, principio y derecho de igualdad -entendida como una igualdad inclusiva.

Ha expresado el Comité sobre los Derechos de las Personas con Discapacidad que la igualdad inclusiva se desarrolla a lo largo de toda la Convención, ampliando y detallando el contenido de la igualdad en las siguientes dimensiones:

e) a) una dimensión redistributiva justa para afrontar las desventajas socioeconómicas; b) una dimensión de reconocimiento para combatir el estigma, los estereotipos, los prejuicios y la violencia,

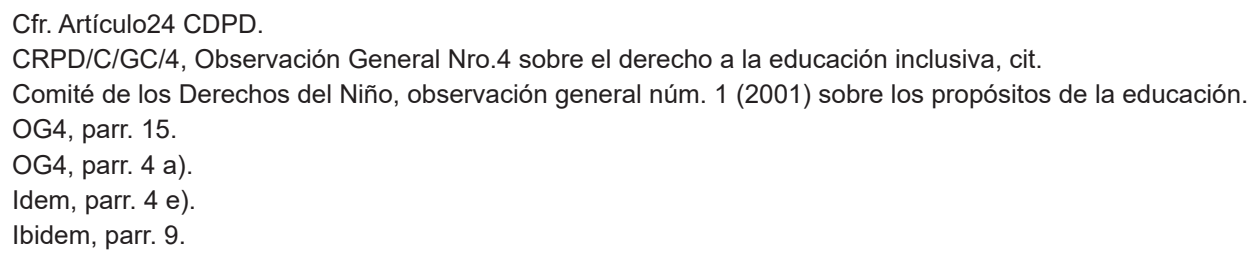


y para reconocer la dignidad de los seres humanos y su interseccionalidad; c) una dimensión participativa para reafirmar el carácter social de las personas como miembros de grupos sociales y el reconocimiento pleno de la humanidad mediante la inclusión en la sociedad; y d) una dimensión de ajustes para dar cabida a la diferencia como aspecto de la dignidad humana. ${ }^{28}$

En este escenario de inclusión entra en juego una herramienta, tan conveniente como imprescindible: la accesibilidad, entendida como "una condición previa y un medio para lograr la igualdad de hecho para todas las personas con discapacidad". ${ }^{29}$ EI Comité en su OG4 ha expresado que los artículos 9 - accesibilidad - y 24 - educación- se encuentran íntimamente vinculados.

f) La accesibilidad es una condición previa para que las personas con discapacidad puedan participar plenamente y en pie de igualdad en la sociedad. [...] Los modos y medios de enseñanza deben ser accesibles y la actividad docente debe llevarse a cabo en entornos accesibles. Todo el entorno de aprendizaje de los alumnos con discapacidad debe diseñarse de tal forma que fomente la inclusión. La educación inclusiva es también un instrumento eficaz para la promoción de la accesibilidad y el diseño universal. ${ }^{30}$

\subsection{Algunas notas sobre la accesibilidad universal, los ajustes razonables y los apoyos como parte del contenido esencial del derecho a una educación inclusiva}

Es sabido que las barreras que enfrentan las personas con discapacidad a la hora del ejercicio de sus derechos son la consecuencia del diseño de una sociedad pensada solo para una persona estándar (cuyo modelo, entre otras condiciones, suele ser caracterizado a partir de un hombre, sin discapacidad). Para eliminar estas barreras, la CDPD brinda algunas estrategias, que requieren de una mirada amplia e inclusiva de la diversidad humana.

La principal estrategia es la accesibilidad universal, que es la condición que garantiza que todas las personas puedan, accedan y participen. Se encuentra implícita para el ejercicio de los derechos, y forma parte de su contenido esencial. (DE ASIS et al., 2007). Para alcanzar esta condición de accesibilidad se cuenta con dos estrategias complementarias. El diseño universal y los ajustes razonables. El primero consiste en concebir o proyectar, desde el origen, entornos, procesos, bienes, productos, servicios, objetos, instrumentos, dispositivos o herramientas, de tal forma que puedan ser utilizados por todas las personas. Mediante la técnica del diseño universal se aspira a la realización de la accesibilidad universal. Es un medio, un instrumento, una actividad, dirigida al alcance de dicho fin. ${ }^{31}$ Los ajustes razonables son aquellas medidas destinadas a adaptar el entorno a las necesidades específicas de ciertas personas, que, por diferentes causas, se encuentran en una situación especial, que no ha podido ser prevista a través del diseño universal. Estas medidas tienden a facilitar la participación en igualdad de condiciones. ${ }^{32}$

Debe sumarse al contenido del derecho a una educación inclusiva, como medidas para su accesibilidad, los sistemas de apoyos. Los entornos educativos deben ser accesibles y disponer de apoyos adecuados. ${ }^{33}$ El artículo 24 establece la obligación de prestar "el apoyo necesario a las personas con discapacidad, en el marco del sistema general de educación, para facilitar su formación efectiva;" [...] así como que se"faciliten medidas de apoyo personalizadas y efectivas en entornos que fomenten al máximo el desarrollo académico y social, de conformidad con el objetivo de la plena inclusión".

Los apoyos a las personas con discapacidad comprenden, en palabras de la Relatora de Naciones Unidas

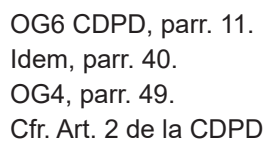

Complementando esta definición, la CDPD establece un concepto de discriminación que es configurada como "cualquier distinción, exclusión o restricción por motivos de discapacidad que tenga el propósito o el efecto de obstaculizar o dejar sin efecto el reconocimiento, goce o ejercicio, en igualdad de condiciones, de todos los derechos humanos y libertades fundamentales en los ámbitos político, económico, social, cultural, civil o de otro tipo", Cfr. Art.2.

33 OG4, parr.12, c) 
g) una amplia gama de intervenciones de carácter oficial y oficioso, como la asistencia humana o animal y los intermediarios, las ayudas para la movilidad, los dispositivos técnicos y las tecnologías de apoyo. También incluye la asistencia personal; el apoyo para la adopción de decisiones; el apoyo para la comunicación, como los intérpretes de lengua de señas y los medios alternativos y aumentativos de comunicación; el apoyo para la movilidad, como las tecnologías de apoyo o los animales de asistencia; los servicios para vivir con arreglo a un sistema de vida específico que garanticen la vivienda y la ayuda doméstica; y los servicios comunitarios. Las personas con discapacidad pueden precisar también apoyo para acceder a servicios generales como los de salud, educación y justicia, y utilizar esos servicios. ${ }^{34}$

El Comité sobre los Derechos de las Personas con Discapacidad ha explicado que las personas con discapacidad deben tener derecho a recibir el apoyo necesario que les facilite su formación efectiva y les permita desarrollarse en pie de igualdad con los demás. ${ }^{35}$ Asimismo, se ha hecho hincapié en la necesidad de

h) ofrecer planes educativos individualizados que puedan determinar los ajustes razonables y el apoyo concreto necesarios para cada alumno, entre otros medios proporcionando ayudas compensatorias de apoyo, materiales didácticos específicos en formatos alternativos y accesibles, modos y medios de comunicación, ayudas para la comunicación, y tecnologías de la información y auxiliares. El apoyo también puede consistir en un asistente de apoyo cualificado para la enseñanza, compartido entre varios alumnos o dedicado exclusivamente a uno de ellos, dependiendo de las necesidades del alumno. [...] El alumno debe tener acceso a mecanismos de recurso si el apoyo no está disponible o es insuficiente. ${ }^{36}$

Finalmente, el Comité ha remitido a su observación general núm. 1 (2014) sobre el igual reconocimiento como persona ante la ley, destacando

i) que la educación inclusiva ofrece a los alumnos con discapacidad, en particular a aquellos con discapacidades psicosociales o intelectuales, la oportunidad de expresar su voluntad y sus preferencias. Los Estados partes deben velar por que la educación inclusiva contribuya a fomentar la confianza de los alumnos con discapacidad en el ejercicio de la capacidad jurídica, prestando el apoyo necesario en todos los niveles de la enseñanza, entre otros fines para reducir las futuras necesidades de servicios de apoyo si así lo desean. ${ }^{37}$

Todas estas facetas o dimensiones de la accesibilidad universal (como condiciones, medidas, ajustes y/o apoyos) deben ser configuradas como parte del contenido esencial del derecho a la educación inclusiva. Y las obligaciones que produce, en términos de estándares, ajustes razonables y apoyos personalizados, se extienden a los espacios físicos, a las relaciones comunicativas, a las barreras actitudinales, a los métodos de enseñanza, a los planes de estudio, a las formas de evaluación y a todas las prácticas pedagógicas y didácticas. (MONTOYA; RUA SERNA; VALENCIA IBAÑEZ, 2018, p. 60). Y se extiende -o debe extendersea la inclusión de la perspectiva de discapacidad y derechos humanos como paradigma, como herramienta analítica, como marco teórico y metodológico en los diferentes ámbitos y escenarios educativos.

\section{Conclusiones}

El Comité sobre los Derechos de las Personas con Discapacidad ha puesto énfasis en la necesidad de diferenciar entre la exclusión, la segregación, la integración y la inclusión educativa. Ni la exclusión en la que se priva a las y los estudiantes de cualquier tipo de educación por motivo de su discapacidad -, ni la segregación - en la que se les imparte una educación separada de sus pares sin discapacidad -, ni la integración - en la que se les "integra" en la medida que se acomoden a lo entendido como "normal" materializan ni conforman el derecho a la educación. ${ }^{38}$ Es sabido que solo la inclusión, en la que las y los

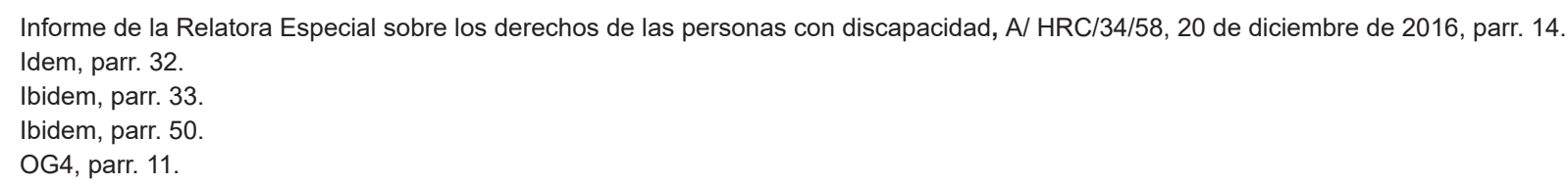


estudiantes se encuentran en un entorno que se adapta a ellos (y no viceversa), satisface verdaderamente este derecho (CORREA MONTOYA; RÛA SERNA; VALENCIA IBÄÑEZ, 2018, p. 58).

Excluir, segregar, integrar, incluir... Cabe preguntarnos dónde nos encontramos en materia de educación superior. Y la respuesta no nos conduce a una zona de justicia. El camino que queda por recorrer es muy largo, y parece presentar muchas barreras. Es por ello que también cabe preguntarnos si la universidad quiere seguir reproduciendo patrones, conductas, modelos, opresiones... o si las quiere transformar. Si la respuesta es lo segundo, entiendo que un primer paso en este arduo camino pasa por -"habilitar" la participación de personas con discapacidad. Y habilitamos desde las políticas de reconocimiento (MARION YOUNG, 2000), desde la garantía de condiciones de accesibilidad, desde la prestación de servicios de apoyo y/o asistencia, desde la adopción de ajustes razonables...

Pero también habilitamos desde la inclusión de la perspectiva de discapacidad y derechos humanos en los programas de estudio, en la investigación, en la extensión y en la transferencia. Ámbitos en los cuales debemos tomar conciencia de nuestra obligación de hacerlo de manera inclusiva. A dicho fin es importante diferenciar entre la educación, investigación, extensión y/o transferencia "sobre inclusión" y la educación, investigación, extensión y/o transferencia "inclusiva". Se hace necesario fortalecer una construcción inclusiva del conocimiento, en la que se ponga en valor las voces de las y los protagonistas. En donde además los caminos narrativos sean caminos inclusivos, donde se asuma el significado que cada persona otorga a sus vivencias. En donde exista una mirada social sobre los procesos de exclusión e inclusión, trascendiendo el foco desde las supuestas dificultades de las personas hacia las barreras que impone la sociedad. Y donde exista una verdadera voluntad y compromiso con la transformación de la sociedad (PARRILLA, 2009, p. 111).

La perspectiva de discapacidad y derechos humanos es uno de los factores centrales si queremos llegar a ser parte del cambio, a contribuir en una verdadera inclusión y a favorecer el goce de derechos. Un primer paso debería ser la incorporación de ciertos contenidos elementales en la materia, desde una mirada trasdisciplinar, interseccional y transversal. Estos contenidos deberían irradiar y replicar dentro de las currículas de formación obligatoria de las diferentes carreras y/o formaciones los nuevos paradigmas en la materia.

Para ello será necesario profundizar en la elaboración de contenidos teóricos sobre discapacidad y derechos humanos desde esta mirada transdisciplinar, transversal e interseccional, y de propuestas para su incorporación en la formación y las prácticas e intervenciones profesionales. Desde la profundización en la articulación de la praxis académica con la participación de sus protagonistas, para transformar conjuntamente las realidades sociales. A dicho fin, parece necesario generar instancias de retroalimentación y enriquecimiento en la formación, validando la interacción comunitaria, y promoviendo la formación de estudiantes futuros/as profesionales responsables y receptivos/as a una realidad y a un contexto del que serán partícipes y/o hacedores/as.

Porque como expresa Adela Cortina (2012), buen/a profesional "no es el simple técnico, el que domina técnicas sin cuento, sino el que, dominándolas, sabe ponerlas al servicio de las metas y los valores de su profesión, un asunto que hay que tratar desde la reflexión y el compromiso éticos".

\section{Referencias}

ACUÑA, Carlos, H.; BULIT GOÑI, Luis, G. (comp.). Políticas sobre discapacidad en Argentina: el desafío de hacer realidad los derechos. Buenos Aires: Siglo XXI Editores, 2010.

BARIFFI, Francisco J. El régimen jurídico internacional de la capacidad jurídica de las personas con discapacidad. Madrid: Cinca, 2014.

BARNES, C.; MERCER, G. Disability. Cambridge: Polity Press, 2003.

BARNES, Colin. Las teorías de la discapacidad y los orígenes de la opresión de las personas discapacitadas en la sociedad occidental. En: BARTON, Len (comp.). Discapacidad y sociedad. Madrid: Morata S.L.,1998. p. 59-76. 
BARRERE UNZUETA, María Ángeles. La interseccionalidad como desafío al mainstreaming de género en las políticas públicas. Revista Vasca de Administración Pública, Espanha, n. 87-88, p. 225-252, 2010. ISSN: 0211-9560.

BROGNA, Patricia. Visiones y revisiones de la discapacidad. México: Fondo de Cultura Económica, 2009.

BRU, Gabriela S. Subjetividad, biopolítica y cuerpo: reflexiones acerca de las prácticas de atención en el campo salud mental. Revista Latinoamericana de Estudios sobre Cuerpos, Emociones y Sociedad, Córdoba, año 8, n. 21, p. 37-51, ago./nov. 2016. ISSN 1852-8759.

BRU, Gabriela S. La interdisciplina como utopía. Margen, [S.I.], n. 67, p. 1-8, dic. 2012.

CORTINA, Adela. Ética en la escuela: formar ciudadanos responsables es el único modo de contar con buenos profesionales. El País, Madrid. 2 nov. 2012.

CORREA MONTOYA, Lucas; RÛA SERNA, Juan Camilo; VALENCIA IBÄÑEZ, María.

\#EscuelaParaTodos: panorama y retos del derecho a la educación inclusiva de las personas con discapacidad en Colombia. Bogotá: DescLAB, 2018.

CROW, Lis. Including all for our lives: renewing the social model of disability. En: BARNES, Colin; MERCER, Geof. Exploring the Divide. Leeds: The Disability Press, 1996. p. 55-72.

CUENCA GÓMEZ, Patricia. Estudios sobre los derechos de las personas sordas. Madrid: Dykinson, 2011.

DE ASIS ROIG, Rafael et al. La accesibilidad universal en el derecho. Madrid: Dykinson, 2007.

DE ASIS ROIG, Rafael. Sobre discapacidad y derechos. Madrid: Dykinson, 2013.

DEMARCHI, Nora; LAZZAR, Marta. El derecho a la educación, desde la accesibilidad al medio físico y comunicacional: política pública y experiencias de las Universidades Nacionales Públicas de la República Argentina. Red Universitaria sobre Derechos Humanos y Democratización para América Latina, Buenos Aires, año 3, n. 6, dic. 2014. p. 89-114.

FERNANDEZ, S.E. El rol del asesor de incapaces en los procesos de salud mental como herramienta de protección reforzada ante la vulnerabilidad. Revista de Actualidad en Derecho de Familia en el Código Civil y Comercial, Buenos Aires, n. 6, 2016.

FERREIRA, Miguel Ángel. La construcción social de la discapacidad: habitus, estereotipos y exclusión social. Nómadas - Revista Crítica de Ciencias Sociales, Madrid, v. 17, n. 1, p. 221-232, 2008.

GOLDSCHMIDT, Werner. Introducción filosófica al derecho. 5. ed. Buenos Aires: Depalma, 1976.

IANANTUONY, Carola. El trabajo social en el campo de la salud mental: prácticas de reproducción y/o prácticas de transformación Una mirada epistemológica. Diporets.org, Mar del Plata, p. 1-9, 2013.

IGLESIAS, María Graciela. Modelos de apoyo, como construir un apoyo. Revista de Derecho Privado y Comunitario. Derecho de Familia II. Buenos Aires, 2016.

LIDÓN HERAS, Leonor. La discapacidad en el espejo y en el cristal: derechos humanos, discapacidad y toma de conciencia, artículo 8 de la Convención Internacional sobre los Derechos de las Personas con Discapacidad, un camino previo por recorrer. Madrid: CERMI, 2016.

MAREÑO SEMPERTEGUI, Mauricio. La discapacidad en la dimensión académica de la Universidad Nacional de Córdoba: una aproximación diagnóstica, Departamento de Discapacidad de la Central de Trabajadores Argentinos (CTA), Programa de Promoción de la Investigación. Secretaría de Investigación y Postgrado. Córdoba: Escuela de Trabajo Social. UNC, 2006.

MENDEZ, Rubens R. "El Acceso a...¿ ¿ónde? La "domesticidad" como elemento de análisis sobre la "intersección" existente entre mujer y discapacidad". Revista Universitas, Madrid, n. 23, 2016. EISSN: 1698-7950.

NUSSBAUM, Martha. Las fronteras de la justicia: consideraciones sobre la exclusión. Traducción de Ramon Vilà Vernis y Albino Santos Mosquera. Madrid: Paidos Iberica, 2012. 
PALACIOS, Agustina; ROMANACH CABRERO, Javier. El modelo de la diversidad: la bioética y los derechos humanos como herramientas para alcanzar la plena dignidad en la diversidad funcional. Madrid: Diversitas, 2007.

PALACIOS, Agustina. El modelo social de discapacidad: orígenes, caracterización y Plasmación en la Convención Internacional sobre los Derechos de las Personas con Discapacidad. Madrid: Cinca, 2008.

PARRILLA, A. ¿Y si la investigación sobre inclusión no fuera inclusiva? Reflexiones desde una investigación biográfico-narrativa. Revista de Educación, [S.I.], v.349, p. 101-117, mayo-agosto 2009.

PAUTASSI, Laura. El aporte del enfoque de derechos a las políticas sociales. Una breve revisión. CEPAL, Naciones Unidas, Enero 2010.

PEÑUELA VELAZQUEZ, Alejandro. La transdisciplinariedad: más allá de los conceptos, la dialéctica. Andamios, México, v. 1, n. 2, jun. 2005.

PÉREZ DE LARA, Nuria. Prólogo a SKLIAR, Carlos ¿Y si el otro no estuviera ahí? Buenos Aires: Miño y Dávila, 2002.

QUINN, G.; DEGENER, T. Derechos humanos y discapacidad: uso actual y posibilidades futuras de los instrumentos de derechos humanos de las Naciones Unidas en el contexto de la discapacidad. Nueva York, 2002.

RODRIGUEZ HERRERO, Pablo; RUIZ AMBIT, Sandra. Granada. Ética de la Educación Inclusiva. En: GARCIA SEMPERE Pablo; PINARGOTE, Maricela; VÉLIZ, Vicente; HERRÁN, Agustin (coord.). Formación y transformación para la educación inclusiva en la universidad. Granada: Universidad de Granada, 2017. p. 65-76.

SERRA, María Laura. Mujeres con discapacidad: sobre la discriminación y opresión interseccional. Madrid: Dykinson, 2017.

SHAPIRO, Joseph P. No pity: people with disabilities forging a new civil rights movement. New York: Times Books: Random House, 1994.

SLAVIN Estefanía. Fundamentos para una "Carta por el Derecho a la Ciudad para el Partido de General Pueyrredón” desde la accesibilidad al patrimonio como Derecho Humano. En: SLAVIN, Pablo (comp.).

Construyendo justicia espacial: convocatoria para la construcción de una Carta por el Derecho a la Ciudad para el Partido de General Pueyrredón, Mar del Plata: UNMDP, 2019. p. 149-160. ISBN 978-987544-912-1.

YOUNG, I. M. La justicia y la política de la diferencia. Traducción de Silvina Álvarez. Madrid:

Ediciones Cátedra: Universidad de Valencia: Instituto de la Mujer, 2000.

Recebido em: 16/11/2019

Aprovado em: 26/11/2019 